\title{
Spectrum of abnormal epithelial lesions of cervix in a tertiary care teaching hospital in South India
}

\author{
Sravani $\mathbf{P}^{1}$, Neeraja $\mathbf{M}^{2}$, Bhavani $\mathbf{C}^{3}$, Varalakshmi K.P \\ ${ }^{1}$ Dr. P. Sravani, Assistant Professor, ${ }^{2}$ Dr. M. Neeraja, Professor \& HOD, ${ }^{3}$ Dr. C. Bhavani, Associate Professor, \\ ${ }^{4}$ Dr. K. P.Varalakshmi, Associate Professor; all authors are attached with Department of Pathology, Government Medical \\ College, Anantapuramu, Andhra Pradesh, India.
}

Address for Correspondence: Dr. P. Sravani, Email: chenna2593@gmail.com

\begin{abstract}
Introduction: Cervical cancer is the leading cause of death in developing countries like India. Cervical cytology by papanicolaou (pap) smears is an effective means of screening for cervical premalignant and malignant lesions. Aim: To study the role of pap smear in detecting premalignant and malignant lesions of cervix and to determine the prevalence of various lesions. Materials and Methods: This was a retrospective study of 1030 conventional pap smears reported from the Department of Pathology, Government Medical College, Anantapuramu. The time period was from October $2014-$ September 2016. Results: In our study out of 1030 cases, inflammatory smears were reported in 713 cases $(69.22 \%)$ ,Epithelial cell abnormalities were found in 71 smears(6.89\%), atypical squamous cells of undetermined significance (ASCUS) in $27(2.62 \%)$, AGUS in $0.10 \%$, LSIL in 25 cases $(2.43 \%)$, HSIL in $1.26 \%$ cases and invasive squamous cell carcinoma in $5(0.48 \%)$ cases.
\end{abstract}

Key words: Cervical cytology, Papanicolaou (pap) smears, Cervical cancer

\section{Introduction}

Cervical cancer is the second most common cancer in women worldwide after breast cancer [1]. In India and other developing countries cervical cancer is the leading cause of morbidity and mortality [2]. It is estimated that in India 1,26,000 new cases occur each year[3]. Unlike most other malignancies cancer of Cervix is readily preventable as it is easy to detect and treat its precursor lesions [4].

The easy accessibility of the cervix and the propensity of the cancer cells to exfoliate from its surface has enabled us to study the process of malignant transformation in the cervix in very early stage [5]. The papanicolaou (Pap) smear was introduced in 1941 and became the standard screening test for cervical cancer and premalignant lesion [6]. Cervical epithelial cell abnormalities in the pap smear represent a spectrum of intraepithelial lesions from mild to severe dysplasia to invasive carcinoma [7].

Manuscript received: $7^{\text {th }}$ May 2017

Reviewed: $16^{\text {th }}$ May 2017

Author Corrected: $24^{\text {th }}$ May 2017

Accepted for Publication: $31^{\text {st }}$ May 2017
The Bethesda system (2001) has been widely used by different Pathologist for interpretation of cervical cytology to have uniform terminology and emphasized communication of clinically relevant information which can be used for further patient management [8].

\section{Aims \& Objectives}

The aim of the study is:-

- To study the role of Pap smear in detecting premalignant and malignant lesions of cervix.

- To determine the prevalence of various lesions of cervix (Inflammatory and Neoplastic).

\section{Materials \& Methods}

This was a retrospective cohort study done at Department of pathology, Government medical college/ Government general hospital, Anantapuramu during October 2014 to September 2016. A total of 1030 pap smears were screened from women aged 20-75 years. 


\section{Inclusion Criteria}

Patients presenting with complaints of vaginal discharge, backache, dyspareunia and post coital bleeding were included in the study. Age of the patients is between 20-75 years.

\section{Exclusion criteria}

Women with invasive cervical carcinoma at the time of clinical evaluation and women already treated with cervical carcinoma.

Complete clinical history and relevant information was obtained from the hospital records and recorded in a proforma. The H \& E slides of these 1030 cases were taken from the cytology filing section in the Department of pathology and the reporting was done by a single pathologist to overcome the observer bias using the guidelines of the 2001 Bethesda system [9].

The result of cervical smears were reported as normal smear, inadequate smear, inflammatory smear, atypical squamous cell of undetermined significance (ASCUS), low grade squamous intraepithelial lesion (LSIL) and high grade squamous intraepithelial lesion (HSIL), squamous cell carcinoma (SCC), Adenocarcinoma (ADE) and atypical glandular cell of undetermined significance (AGUS).

Data were coded and entered into microsoft excel worksheet. The results were expressed in percentages and proportions.

\section{Results}

A Total of 1030 cases were analyzed during a period of two years. The age of women ranged from 22 to 74 years. Maximum number of patients i.e., 39.51\% were in the age group of 31-40 years (fourth decade) followed by $33.01 \%$ in third decade as shown in table I. Sixty seven ( 6.50\%) smears were found to be unsatisfactory for evaluation.

892 smears were reported as negative for intraepithelial lesion or malignancy (NILM). Out of 892 NILM smears, 179 (17.38\%) showed normal cytological findings and $713(69.22 \%)$ were inflammatory. Out of 713 inflammatory smears, $685(66.50 \%)$ shown Non specific inflammation, $12(1.16 \%)$ had features of Gardenella infection, $9(0.87 \%)$ had evidence of Trichomonas as shown in figure I and $7(0.68 \%)$ showed features of Candida infection. The inflammatory lesions were seen predominantly in $2^{\text {nd }}$ and $3^{\text {rd }}$ decade.

Epithelial cell abnormalities were found in 6.89\% (71 cases) as shown in table II. The diagnosis of 71 abnormal cases revealed 27 cases with ASCUS (2.62\%), 25 cases (2.43\%) of LSIL as shown in figure II, 13 cases (1.26\%) of HSIL as shown in figure III, 5 cases $(0.48 \%)$ of invasive squamous cell carcinoma as shown in figure IV and one case of AGUS $(0.10 \%)$.

Mean age of the patients with ASCUS was 24 years, LSIL was 29 years, HSIL was 38.5 years, SCC was 55 years. ASCUS and LSIL were seen predominantly in 21-30 years age group, HSIL in 31-40 years age group and SCC in sixth decade as shown in table III.

Table-I: Age wise distribution of the cases.

\begin{tabular}{|c|c|c|}
\hline Age Group (Years) & No. of. Cases & Total (\%) \\
\hline $21-30$ & 340 & $33.01 \%$ \\
\hline $31-40$ & 407 & $39.51 \%$ \\
\hline $41-50$ & 178 & $17.28 \%$ \\
\hline $51-60$ & 80 & $7.77 \%$ \\
\hline$>60$ & 25 & $2.43 \%$ \\
\hline Total & $\mathbf{1 0 3 0}$ & $\mathbf{1 0 0 \%}$ \\
\hline
\end{tabular}


Table-II: Categorisation of cases based on cytodiagnosis.

\begin{tabular}{|l|c|c|}
\hline Cytodiagnosis & No. of .Cases & Percentage \\
\hline Unsatisfactory & 67 & $6.50 \%$ \\
\hline NILM & $\mathbf{1 7 9}$ & $\mathbf{1 7 . 3 8 \%}$ \\
Normal & $\mathbf{7 1 3}$ & $\mathbf{6 9 . 2 2 \%}$ \\
\hline Inflammatory & 685 & $66.50 \%$ \\
\hline$\bullet$ Nonspecific inflammation & 12 & $1.17 \%$ \\
\hline$\bullet$ Gardenella & 9 & $0.87 \%$ \\
\hline$\bullet$ Trichomonas & 7 & 0.68 \\
\hline$\bullet$ Candida & $\mathbf{7 1}$ & $\mathbf{6 . 8 9} \%$ \\
\hline Epithelial cell abnormalities & 27 & $2.62 \%$ \\
\hline$\bullet$ ASCUS & 01 & $0.10 \%$ \\
\hline$\bullet$ AGUS & 25 & $2.43 \%$ \\
\hline$\bullet$ LSIL & 13 & $1.26 \%$ \\
\hline$\bullet$ HSIL & 05 & $0.48 \%$ \\
\hline$\bullet$ SCC & $\mathbf{1 0 3 0}$ & $\mathbf{1 0 0 \%}$ \\
\hline Total & & \\
\hline
\end{tabular}

Table-III: Age wise distribution of epithelial cell abnormalities

\begin{tabular}{|c|c|c|c|c|c|c|c|}
\hline & $\mathbf{2 1 - 3 0}$ & $\mathbf{3 1 - 4 0}$ & $\mathbf{4 1 - 5 0}$ & $\mathbf{5 1 - 6 0}$ & $\mathbf{> 6 0}$ & Total & \% \\
\hline ASCUS & 11 & 09 & 04 & 02 & 01 & 27 & $2.62 \%$ \\
\hline AGUS & -- & 01 & -- & -- & -- & 01 & $0.10 \%$ \\
\hline LSIL & 09 & 07 & 04 & 03 & 02 & 25 & $2.43 \%$ \\
\hline HSIL & -- & 06 & 04 & 02 & 01 & 13 & $1.26 \%$ \\
\hline SCC & -- & -- & 01 & 03 & 01 & 05 & $0.48 \%$ \\
\hline
\end{tabular}

Table -IV: Various parameters of pap smear in present study compared with other studies

\begin{tabular}{|c|c|c|c|c|}
\hline Cytodiagnosis & $\begin{array}{c}\text { Present study } \\
(\mathbf{n = 1 0 3 0})\end{array}$ & $\begin{array}{c}\text { Kalyani } \\
\text { etal[17](n=1501) }\end{array}$ & $\begin{array}{c}\text { Tejaswini } \\
\text { etal[19] }(\mathbf{n = 2 1 0})\end{array}$ & $\begin{array}{c}\text { Sunitha etal[2] } \\
(\mathbf{n}=\mathbf{5 6 0})\end{array}$ \\
\hline Unsatisfactory & $6.50 \%$ & $17.80 \%$ & $0.95 \%$ & $7.40 \%$ \\
\hline ASCUS & $2.62 \%$ & $1.46 \%$ & $2.38 \%$ & $4.00 \%$ \\
\hline AGUS & $0.10 \%$ & $0.24 \%$ & $0.48 \%$ & $00 \%$ \\
\hline LSIL & $2.43 \%$ & $0.24 \%$ & $0.95 \%$ & $1.6 \%$ \\
\hline HSIL & $1.26 \%$ & $0.41 \%$ & $1.43 \%$ & $0.4 \%$ \\
\hline SCC & $0.48 \%$ & $0.41 \%$ & $0.48 \%$ & $0.4 \%$ \\
\hline
\end{tabular}

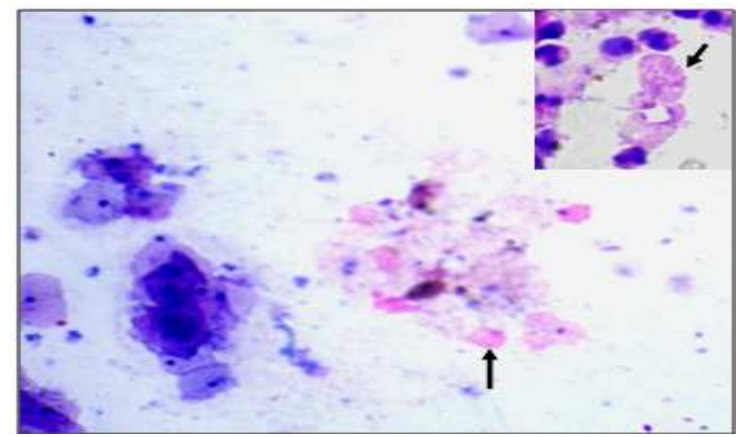

Figure-I: Trichomonas: Arrows indicate trichomonas in $10 \mathrm{X}$ and $40 \mathrm{X}$.

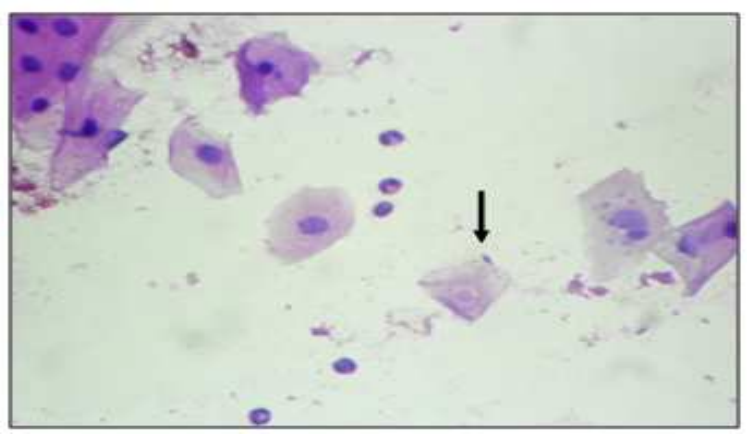

Figure-II: LSIL: Arrow showing koilocyte 


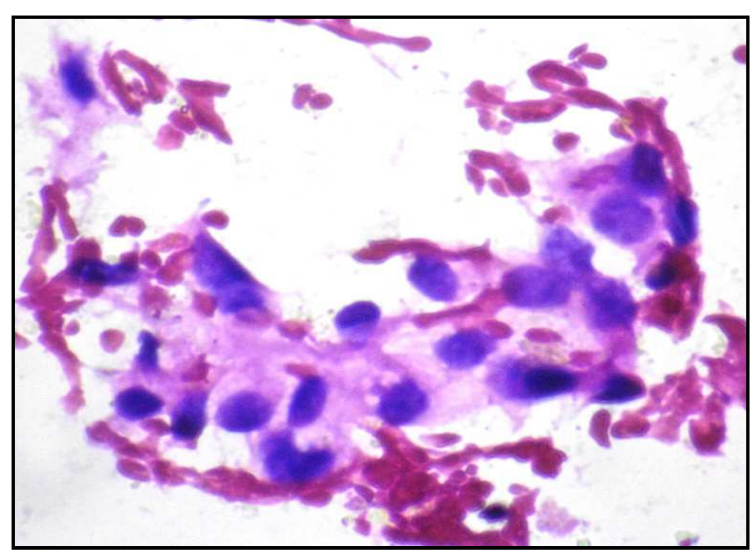

Figure-III: HSIL

\section{Discussion}

With the changes in the life styles and demographic profiles in developing countries, non-communicable diseases are emerging as an important health problem which demand appropriate control program before they assume epidemic propagation [1]. It is the most common cancer among women after breast and colorectal cancer in the world, but in India and other developing countries cervical cancer is the leading cause of mortality and morbidity. Women in these countries usually present to the clinic only when they have symptoms, such as pain, discharge, and/or abnormal bleeding [10].

The worldwide incidence of cervical cancer is 15.3 / 100,000 women per year. Cancer of the cervix uteri is the second most common cancer among women worldwide, with an estimated 529,409 new cases and 274,883 deaths in 2008 . About $86 \%$ of the cases occur in developing countries, representing $13 \%$ of female cancers. The cause of this cancer is attributed to human papillomavirus in $99 \%$ of these cases [11]. Risk factors for cervical squamous carcinoma include early onset of sexual activity, early age of first pregnancy, multiple sexual partners, exposure to human papilloma virus (HPV), cigarette smoking, immunosuppression, human immunodeficiency virus or concomitant neoplasia of vulva or vagina [12].

The target cells for an initial HPV infection are the immature basal cells of the epithelium, and HPV is thought to reach these cells through microabrasions or cracks within the epithelium. Viral replication is tightly linked to the differentiation state of the virally infected epithelial cells. Replication of the HPV genome is

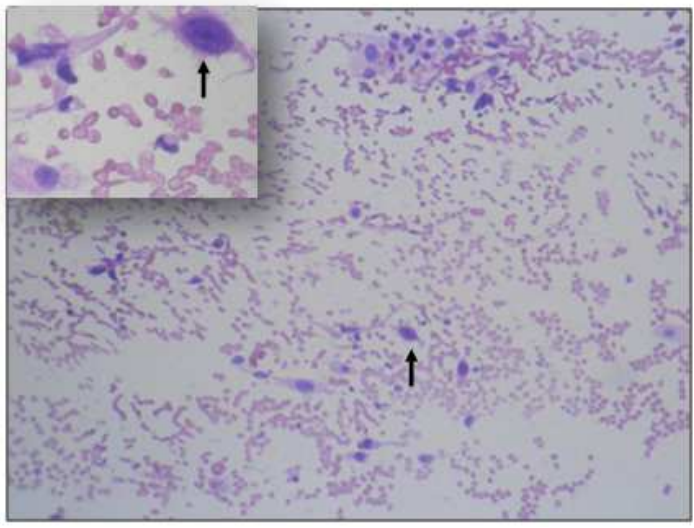

Figure-IV: SCC: Arrows indicate tad pole cells in $10 X$ and $40 X$

tightly controlled by cellular mechanisms within the basal cells, and appears to be linked to cellular replication so that the viral DNA replicates with the host' s genome [13].

Fortunately, infection is usually transient and of no clinical consequence, but a minority of patients retain the oncogenic viruses within their genital epithelium which can lead to the development of cervical intraepithelial neoplasia and possible cancer[10]. Persistent infection by certain oncogenic HPV types is firmly established as the necessary cause of most premalignant and malignant epithelial lesions of the cervix[14].

National Health Services (NHS) in UK concluded that, in any case who developed cancer cervix at the average age 46-50, this may entail that carcinogenesis had started 20 years ago, ie, at the age of 26-30. Hence, screening is better to be started at $>25$ years [15]. There are several methods for cervical cancer screening and several studies have established the importance of papanicolaou (PAP) smear as one of the easy and important screening methods for cervical cancer control [16]. The screening coverage in India is $2.6-6.5 \%$ and is mainly an opportunistic screening [17].

Adequacy and frequency of cytological screening may also play an important role, the risk of developing invasive squamous cell carcinoma in women who had no Papanicolaou smear in the last five years being 3.74.3 times greater than in women who had one in the past two years. The risk of death from invasive cervical carcinoma is highest in women with inadequate 
cytological screening [12]. There should be an effective mass screening programme aimed at specific age group for detecting precancerous condition before they progress to invasive cancer [18].

In our study mean age of patients with LSIL was 29 years, HSIL and invasive carcinoma were 38.5 years and 55 years respectively. Bal.etal ${ }^{3}$ also recorded a progressive increase in development of LSIL to invasive carcinoma with increasing age. Bal.etal [3] found mean age of patients with LSIL, HSIL and invasive carcinoma to be 32.3 years; 40.5 years and 57 years respectively. The results are in concordance with the present study.

This study determines 892 cases $(86.60 \%)$ negative for any intraepithelial lesion or malignancy with non specific inflammation (685 cases $66.50 \%$ ) as the predominant ones. Other studies revealed $86 \%$ and $96.92 \%$ cases of NILM respectively $[1,17]$.

Epithelial cell abnormality rate (ECA) that is the total of into atypical squamous cells of undetermined significance ASCUS, low-grade squamous intraepithelial lesions( LSIL), high-grade squamous intraepithelial lesions (HSIL), atypical glandular cells of undetermined significance (AGUS) and carcinoma diagnosis varied between $3.80 \%$ and $26.31 \%$ in various studies $[17,19,8,5]$. The ECA rate of $6.89 \%$ in our study was comparable to the study done by vaddatti Tejeswini et al [19] i.e., 5.7\%.

Our study revealed ASCUS (2.62\%) to be the most common epithelial cell abnormality. Similar results were obtained in other studies which also concluded ASCUS to be the most common epithelial cell abnormality as shown in table -IV [17, 19]. The lower incidence of LSIL in these studies might be because of their cultural traditions and great concern regarding their health checkups. The incidence rate of LSIL in our study is seen in $2.43 \%$ cases which are more compared with various studies.

In our study HSIL is seen in $1.26 \%$ of cases which is in comparision with vaddatti tejeswini etal[19] and the incidence is high when compared to other studies[2, 17] which show $0.4 \%$ and $0.41 \%$ respectively. The increased incidence of HSIL in our study might be because of early age at marriage and early sexual activity.SCC is seen in $0.48 \%$ of cases which is in comparision with various studies[2,17,19] as shown in table-IV. Our study thus elucidates the importance of papanicolaou cervical screening test.

\section{Conclusion}

This study emphasized the importance of pap smears screening for early detection of premalignant and malignant lesions of cervix. The incidence of premalignant and malignant lesions is not uncommon in our set up and high raised prevalence of these lesions reflects the lack of awareness among people about cervical cancer screening programmes. Each and every government and non-governmental agency has to sensitize the public regarding this preventable cancer of cervix.

\section{Funding: Nil, Conflict of interest: None Permission of IRB: Yes}

\section{References}

1. Rathore SB, Atal R. Study of Cervical Pap Smears in a Tertiary Hospital. International Journal of Science and research (IJSR). 2016;5(5): 2071-2074.

2. Bamanikar SA, Baravkar DS, Chandanwale SS, dapkekar P. Study of Cervical Pap Smears in a Tertiary Hospital. Indian Medical Gazette. 2014:250-254. DOI: http://dx.doi.org/10.18203/2320-6012.ijrms20160044.

3. Bal MS, Goyal R, Suri AK, Mohi MK. Detection of abnormal cervical cytology in Papanicolaou smears. Journal of cytology. 2012 Jan 1; 29(1):45-7.DOI: $10.4103 / 0970-9371.93222$

4. Jena A, Bharathi T, Siva Kumar Reddy YK, Manilal B, Patnayak R, Phaneendra BV. Papanicolaou (Pap) test screening of staff members of a tertiary care teaching hospital in south India. J.Clin Sci. Res.,2012;1:174-7.

5. Bhojani KR, Garg R. Cytopathological study of cervical smears and correlation of findings with risk factors. Int J Biol Med Res. 2011;2(3):757-61.

6. Vaghela B, Vaghela VK, Santwani PM. Profile of PAP smear cytology and its histopathological correlation at tertiary care center-A retrospective study. International Journal of Biomedical and Advance Research. 2014 Jan 30;5(1):47-9. DOI:10.7439/ijbar.

7. Bhattacharya AB, Agarwal A, Dwivedi AD, Khan S, Das R, Bohara S, Sharma R. Uterine Cervical Smear 
Patterns In Females Attending A Teaching Hospital In Rural Eastern Uttar Pradesh, INDIA. IOSR Journal of Dental and Medical Sciences (IOSR-JDMS). 2016;1(15):45-9. DOI: 10.9790/0853-15090 24549.

8. Dr. Rupal P. Mehta, Dr. Alpa Shah, Dr. T. Y. Vijapura, Dr. Himanshu P. Patel Study of Epithelial Abnormalities in Cervical Smear of Perimenopausal and Postmenopausal Women. International Journal of Scientific Research.2013; 2(7):326-28. DOI : 10.15373/ 22778179.

9. Diane Solomon; Diane Davey; Robert Kurman; et al. The 2001 Bethesda System: Terminology for Reporting Results of Cervical Cytology. JAMA. 2002; 287 (16): 2114-2119(doi:10.1001/jama.287. 16.2114).

10. Thirumurugan $P$, Premila E, Suresh kanna K. Study of early detection of cervical cancer by pap's smear in selected setting of puducherry. Asia pacific journal of research.2015;1(34):156-160.

11. Mufti ST, Altaf FJ. Changing pattern of epithelial cell abnormalities using revised Bethesda system. Iranian Journal of Basic Medical Sciences. 2014; 17(10):779-784.

12. Proca DM, Rofagha S, Keyhani-Rofagha S. High grade squamous intraepithelial lesion in inmates from Ohio : Cervical screening and biopsy follow-up. CytoJournal 2006; 3:15. DOI: 10.1186/1742-6413-3-15.

13. Thomas C. Wright, Jr. Pathology of HPV infection at the cytologic and histologic levels: Basis for a 2- tiered morphologic classification system. International Journal of Gynecology and Obstetrics (2006) 94 (Supplement 1), S22-S3.

14. Rubia Noreen, Huma Qudussi.'Pap smear' for screening of precancerous conditions of cervix. J Ayub Med Coll Abbottabad 2011; 23(2) 41-4.

15. Balaha MH, Al Moghannum MS, Al Ghowinem N, Al Omran S. Cytological pattern of cervical papanicolaou smear in eastern region of Saudi Arabia. J Cytol 2011; 28:173-7.DOI:10.4103/0970-9371.86343.

16. Nandwani RR, Totade S, Krishnan MG. Cytomorphological evaluation of squamous cell abnormalities observed on cervical smears in government medical college, Jabalpur, India: a five year study. Int J Res Med Sci 2016;4(3):794-9.DOI: http://dx.doi.org/10. 18203/2320-6012.ijrms20160520 .

17. Kalyani R, Sharief N, Shariff S. A study of Pap smear in a Tertiary Hospital in south India. J Cancer Biol Res. 2016;4(3):1084.

18. Mandakini M Patel, Amrish N Pandya, Jigna Modi . Cervical Pap smear study and its utility in cancer screening, to specify the strategy for cervical cancer control. National Journal of community medicine, 2011;2(1):49-51.

19. Tejeswini V, Premalatha P. Pap smear examinationits utility in various cervical lesions. Indian Journal of Pathology and Oncology. 2016;3(2):242-6.

\section{How to cite this article?}

Sravani P, Neeraja M, Bhavani C, Varalakshmi K.P. Spectrum of abnormal epithelial lesions of cervix in a tertiary care teaching hospital in South India. Int J Med Res Rev 2017;5(05):472-477. doi:10.17511/ijmrr. 2017.i05.06. 